\title{
Sobre la conveniencia o no de establecer congregaciones de indios en los reales de minas
}

\author{
Francisco Luis Jiménez Abollado*
}

UNIVERSIDAD AUTÓNOMA DEL ESTADO DE HIDALGO

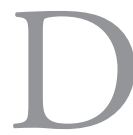

e 1598 a 1605 el virreinato de Nueva España se vio sacudido por una ambiciosa política de reacomodación de los pueblos indios, especialmente en el centro geográfico del mismo, conocida como congregaciones civiles. ${ }^{1}$ El virrey Gabriel de Zúniga y Azevedo, conde de Monterrey, fue su gran impulsor, aunque el proceso reduccionista venía desarrollándose desde antes, y trató de encarar uno de los problemas más acuciantes que afectaba al territorio donde fue a ejercer su gobierno: la drástica disminución de los naturales. El modelo reduccionista aplicado en el virreinato de Perú por el virrey Francisco de Toledo entre 1569 y 1571 fue el que Zúńiga y Azevedo quiso adaptar en Nueva España. ${ }^{2}$ El objetivo era reducir a la vida urbana a los grupos dispersos de indígenas, pero

*fjimab64@prodigy.net.mx

${ }^{1}$ Sobre el fenómeno y el proceso de las congregaciones o reducciones de pueblos de indios en Nueva Espańa pueden consultarse los trabajos de Ernesto de la Torre Villar, "Relación de la congregación del pueblo de Tianguistengo, provincia de Meztitlan" en Boletin del Archivo General de la Nación, 2a serie, tomo xxII, núm 2, abril-junio, México, 1952, Las congregaciones de los pueblos de indios. Fase terminal: aprobaciones y rectificaciones, México, Instituto de Investigaciones Históricas-unam, 1995; Howard F. Cline, "Congregaciones civiles de indios en la Nueva España”, Boletín del Archivo General de la Nación, tomo xxvı, núm. 2, abril-mayo-junio, México, 1955; Peter Gerhard, "Congregaciones de indios en la Nueva España antes de 1570”, Historia Mexicana, vol. xxvı, enero-marzo, 1977, 3: 347-395; Lesley Bird Simpson, Studies in the Administration of the Indians in New Spain, Berkeley, University of California Press, 1934; Bernardo García Martínez, Los pueblos de la Sierra. El poder y el espacio entre los indios del norte de Puebla hasta 1700, México, El Colegio de México, 2005; Hilda J. Aguirre Beltrán, La congregación civil de Tlacotepec (1604-1606), México, Ciesas, Cuadernos de la Casa Chata, 98, 1984.

${ }^{2}$ Howard F. Cline, art. cit., p. 200. 
además, como señala De la Torre Villar, controlar estas poblaciones, sus recursos naturales y su fuerza de trabajo. ${ }^{3}$ El programa por implantar estaba muy estudiado y sistematizado. Para ello se previeron distintas fases de aplicación. La primera, de 1598 a 1599, de visita e inspección; hasta 1602-1603, periodo de debates y planes y, de 1603 a 1605, fase de operaciones y de traslado de los indios de un territorio a otro. ${ }^{4}$

En esos años deben tenerse en cuenta dos realidades evidentes en Nueva España. Por una parte, el cataclismo demográfico de la población indígena causado por el efecto de epidemias y plagas; por otra, la necesidad de mano de obra en los centros mineros, que vivían en los ańos finales del siglo xvi e inicios del siguiente una crisis de producción importante. En este sentido, el sistema de repartimiento utilizado para trabajar en las minas empezó a ponerse en duda para aliviar la carga de las comunidades indígenas y se ofrecieron alternativas para la obtención de mano de obra como la esclavitud negra, la libre contratación y hasta las mismas congregaciones de indios. ${ }^{5}$

A partir de 1570 empezó a generalizarse la presencia de trabajadores libres o naboríos en las minas del centro de la Nueva España, de acuerdo a las descripciones y reportes realizados para las minas de Pachuca e Ixmiquilpan. Su concurso en las minas tendió a incrementarse, en detrimento de los indios de repartimiento, desde finales del siglo xvi como respuesta a la situación social y económica de aquellos tiempos. Muchos indios naboríos que fueron a trabajar a las minas salieron de sus comunidades apremiados por la falta de tierras para cultivar, las enfermedades que diezmaban los pueblos y, también decirlo, por los incentivos de un ingreso fijo y mayor del que podían sacar de sus tareas agrícolas. Por otra parte, las medidas que la Corona impuso para limitar, primero, y abolir, después, el repartimiento laboral, hasta el primer tercio del siglo XVII, no afectó

${ }^{3}$ Ernesto de la Torre Villar, op. cit., pp. 56-57.

${ }^{4}$ Howard F. Cline, art. cit., p. 202.

${ }^{5}$ Véase María del Pilar Martínez López-Cano, "Entre la filosofía moral y la política económica. Los debates sobre el repartimiento o coatequitl en la segunda mitad del siglo xvı", en María del Pilar Martínez López-Cano, Historia del pensamiento económico: testimonios, proyectos y polémicas, México, unam, Instituto Mora, 2009, 15-47. 
al trabajo minero porque, pese al declive de la población indígena y el aumento de los naboríos o trabajadores libres, el sistema del coatequitl representaba siempre una entrada, aunque fuera pequeña, de población indígena trabajadora forzada a cumplir en los reales de minas. Su presencia en estos años, además, amortiguó los efectos de las fluctuaciones existentes en las minas cuando se producían rebajas en los costos de producción y dejaban de contratarse naboríos. ${ }^{6} \mathrm{Se}-$ gún Martínez López-Cano, no faltaron planes de ampliar las comunidades sujetas al repartimiento de las minas e incluso de aumentar sus estadías en las mismas con tandas de dos meses, incluso hasta el ańo, para evitar así, presuponían, el despilfarro de desplazar a los indígenas por solo una semana. ${ }^{7}$

Otra alternativa al sistema de repartimiento, y que podría servir para aportar mano de obra al desarrollo de una actividad económica esencial como era la minería, sería el establecimiento de congregaciones de indios en el entorno de los reales mineros. Existen antecedentes sobre la necesidad de realizar congregaciones o reducciones de indios en los reales de minas novohispanos. En 1584, según recoge Martínez López-Cano, los mineros de Nueva España solicitaron el establecimiento de las citadas congregaciones para que las minas "se conserven y no se acaben, cuya ruina y perdición se espera con mucha brevedad por estar todas ellas desahuciadas y haber venido en tanta disminución". ${ }^{8}$ Los mineros demandaban indios con sus familias, mujeres e hijos, que no fueran de los pueblos comarcanos a las minas, pues éstos aseguraban las actividades agrícolas y ganaderas necesarias para generar los insumos que abastecían las minas. La idea de los mineros era que los indios y sus familias se habían de "perpetuar y naturalizar" en las haciendas mineras pudiendo hacer diferentes labores y recibiendo distintos salarios de acuerdo al trabajo que realizasen. Además, se les daría maíz para su sustento, casas y solicita-

${ }^{6}$ Gilda Cubillo Moreno, Los dominios de la plata: El precio del auge, el peso del poder, México, INAH, 1991, 241-245.

${ }^{7}$ María del Pilar Martínez López-Cano, art. cit. p. 29.

${ }^{8}$ Archivo General de Indias (en adelante AGI), Patronato, 238 núm. 2, "Ciertos mineros de Nueva España piden algunas gracias para beneficiar y conservar las minas de aquel reino, 1584", apud, María del Pilar Martínez López-Cano, art. cit. p. 39. 
rían se les exentase del tributo. Don Pedro Moya, el arzobispo-virrey, se hizo eco de esta solicitud. En 1585 envió al rey de España información de actuaciones en este sentido que estaban realizando los mineros de Pachuca construyendo casas en sus reales de minas para acoger indios con sus mujeres e hijos y buscando su perpetuidad. ${ }^{9}$

La realidad del sector minero en la Nueva España, a fines del siglo XVI, por tanto, no era muy floreciente. A los problemas técnicos y de suministro de azogue se añadían los derivados de la asignación de mano de obra indígena, mermada por la citada crisis demográfica. ${ }^{10} \mathrm{El}$ virrey conde de Monterrey supo del peligro de la situación en este importante rubro de la economía novohispana después de los encuentros que mantuvo con mineros, especialmente el relativo a la mano de obra indígena y la necesidad de que ésta se instalase en los reales de minas. Para los dueńos de minas era urgente solucionar esto último, como ya lo expresaron al rey en 1584. Sin embargo, Zúniga y Azevedo era de la opinión de analizar antes la posibilidad de hacer frente al proceso de congregaciones de pueblos de indios en la Nueva Espańa, y una vez estudiada y vista la viabilidad del mismo poder aplicar el sistema a los reales mineros.

El expediente documental que aquí presentamos, procedente de la sección Audiencia de México del Archivo General de Indias (AGI), revela el interés que en el entorno del virrey conde de Monterrey supuso la posibilidad de introducir el modelo de las congregaciones en los reales de minas novohispanos. ${ }^{11} \mathrm{El}$ expediente muestra diferentes discusiones y propuestas que sobre las congregaciones de pueblos de indios en los reales de minas se generaron en la Nueva Espańa entre 1598 y 1603, así como la opinión personal sobre este asunto del propio virrey. Este actuó, desde su prominente posición política, como árbitro entre juristas y religiosos partidarios de las reducciones de indios en los reales de minas. Las opiniones presentadas juzgaban

${ }^{9}$ Idem.

${ }^{10}$ Véase al respecto, Gilda Cubillo Moreno, op. cit., pp. 191-272; Peter J. Bakewell, Minería y sociedad en el México colonial. Zacatecas (1546-1700), México, FCE, 1984, 305325.

${ }^{11}$ AGI, México, 1844, "De oficio. Si conbendrá hazerse poblaciones de indios en los reales de las minas donde trabajan o fuera de ellas", mayo de 1603, ff. 206r-216v. 
qué sería lo más benévolo para los indígenas, si congregarlos en las inmediaciones de los reales de minas o dentro de los mismos.

El primer documento del expediente corresponde a la copia de una carta que el conde de Monterrey escribió al rey el 2 de diciembre de $1602 .{ }^{12}$ En ella solicitaba respuesta del Consejo de Indias a un capítulo de gobierno sobre la conveniencia de "que las poblaciones de indios en las minas sean dentro o fuera”. La contestación del Consejo tenía que llegar a Nueva España antes de abril-mayo de 1603, una vez que las personas encargadas por el virrey para considerar la conveniencia o no de realizar congregaciones de indios al interior de los Reales de minas hubieran realizado sus respectivos informes.

El siguiente documento corresponde a la copia de un capítulo de una carta, escrita el 25 de mayo de 1602, seis meses antes de la mencionada en el primer documento, donde el virrey Zúniga y Azevedo resume el proceso seguido para considerar el beneficio o no de realizar las congregaciones de indios dentro o fuera de los reales de minas. ${ }^{13}$ En 1598 , iniciada la primera fase de las congregaciones civiles -visita e inspección de los lugares-, el virrey conde de Monterrey hizo reunir a oidores y religiosos para analizar cuál sería el sistema más justo para congregar o reducir indios en los reales de minas, si al interior de las mismas o en sus cercanías. Sin embargo, las determinaciones y deliberaciones no se podían resolver a la ligera y tenían que seguir el ritmo que llevaba el proceso de las congregaciones. Fue hasta 1602 cuando ordenó "que se hiciese últimamente una conferencia delante de mí sobre el punto referido de la situación de las poblaciones dentro de los Reales o fuera”. En ella participaron las dos partes interesadas. Por una parte, el oidor de la Real Audiencia de México, Antonio Maldonado y tres religiosos de la Compañía de Jesús fueron los encargados de realizar y presentar al virrey Zúńiga y Azevedo las alegaciones que creían convincentes, donde sostenían que las congregaciones de indios habían de realizarse fuera de los reales mineros. Por otra, el doctor Luis de Villanueva Zapata, ex fiscal de la Real Audien-

12 "Copia de un capitulo de carta que el conde Monterrey escrivió a Su Majestad en carta de 2 de diciembre de 1602", f. 207r.

13 "Copia de un capítulo de carta del conde de Monterrey para Su Majestad de 25 de mayo de 1602”, ff. 208r-209v. 
cia de Lima y dueño de haciendas de minas, junto a dos alcaldes mayores con experiencia en congregaciones, fueron los comisionados para redactar el pliego defensor de efectuar las congregaciones de pueblos de indios en el interior de los reales de minas. El virrey conde de Monterrey observó que los pareceres entre ambas partes estaban muy encontrados, pero ello no le impidió tomar partido por los defensores de realizar las congregaciones en el interior de los reales de minas, por "ser menores las vejaciones en la población de indios que se asentare dentro que en las vecinas y [...] la experiencia que tienen de las cosas de minas los que fueron ahora de este parecer y el considerar que esta experiencia no la tienen los demás". Zúńiga y Azevedo adoptó una serie de medidas comprendiendo las diferencias entre los participantes y pese a su parecer personal favorable a realizar las congregaciones dentro de los Reales de minas. Ordenó "que en uno o dos asientos de minas se pruebe el poblarlos dentro del real para consultar la experiencia en esta duda”. La experiencia duraría ocho meses, para determinar después cual sería la resolución que tomara el Consejo de Indias. De acuerdo a los tiempos ésta se conocería en los primeros meses de 1603. Para que el Consejo tuviese elementos o criterios para analizar y decidir sobre esta cuestión, el virrey conde de Monterrey envió los informes elaborados por las dos partes.

Los dos informes muestran a las claras las diferencias existentes en relación con el empleo de la mano de obra indígena en una actividad esencial como era la minería. El repartimiento laboral y el trabajo libre pugnaban en estas controversias recurriendo a una nueva política de control y utilización de la población indígena como fue la congregación de pueblos de indios, ${ }^{14}$ aplicada en este caso a los reales de minas.

El informe presentado por Antonio Maldonado, oidor de la Real Audiencia de México, y tres religiosos de la Compañía de Jesús defendía el establecimiento de las congregaciones de indios fuera de los reales mineros. ${ }^{15}$ Las razones que expusieron, intentando demostrar

${ }^{14}$ Ernesto de la Torre Villar, op. cit., pp. 56-57.

15 "Los ynconvenientes que tiene la población de yndios dentro de las minas y la conveniencia que se seguirán haciendo fuera y lo más cerca que se pueda”, ff. 210r-211v. 
la nula disposición de los pueblos de indios a vivir en el interior de los reales de minas junto con otros grupos étnicos, fueron condensadas en siete puntos. En primer lugar, señalaron que la idiosincrasia e inclinación del indio era vivir en el campo, lejos de los españoles, trabajando sus tierras para su sustento y el pago del tributo. El odio natural del indio a trabajar en el servicio de las minas era otra razón que exteriorizaron. La experiencia del repartimiento o coatequitl demostró que si el corto y breve tiempo de trabajo de este sistema compulsivo - una semana- no fue satisfactorio para los indios, el ir obligados a asentarse y vivir en los mismos reales de minas y entre los mineros, fuera de su ambiente y entorno natural, por mucho interés $\mathrm{y}$ ofrecimientos que les pudieran brindar los mineros lo que provocaría sería el abandono de las congregaciones. Además, Maldonado y los padres jesuitas consideraban perjudicial el que los indios viviesen a merced y voluntad de los mineros y no tuviesen posibilidad "de qué sustentarse ni de dónde sacar un tomín sino de lo que el minero le quisiere dar". Argüían la vejación y molestia continuas que soportaron los indios de repartimiento que trabajaban en las minas, no sólo de los mineros, sino de sus criados y esclavos, de día y de noche, asaltando sus casas y robando gallinas y otras pertenencias. Esto podría extenderse a sus mujeres e hijas si se llegasen a formalizar las congregaciones en el interior de los reales de minas. Si se realizaran las congregaciones fuera de los reales de minas se impedirían estas acometidas, además los indios contarían con la defensa del ministro de doctrina asistente y el corregidor.

Las tres últimas razones planteadas por el licenciado Maldonado y los padres jesuitas son recomendaciones a los mineros para ganarse la confianza y qué medios debían usar para que los indios pudieran trabajar en los reales de minas sin tener que congregarlos en su interior. El hecho de que los pueblos se congregaran fuera de las minas era para que la vecindad con los mineros fuera satisfactoria y apacible. Ello permitiría que los indios acudieran a trabajar a las minas, ya fuera a través del servicio personal o el trabajo libre, perdiendo el miedo y el aborrecimiento natural a este trabajo; solo así irán a vivir dentro de los reales de minas, "y viéndolos los demás que de aquello resulta provecho y menos trabajo y riesgo del cual principio imagi- 
narán se irán aficionando otros a este modo de vida y conseguirán los mineros el fin que desean de tener gente". El minero tendría que atraer "con caricia, regalo y buena paga al indio", medios a través de los cuales se aficionarían a las minas y al trabajo en ellas. Para el oidor Maldonado y los padres de la Compañía de Jesús, el escenario laboral más viable de los indios en las minas era el repartimiento de ocho días a un mes, para volverse a sus pueblos donde trabajar sus tierras y descansar ese mismo periodo de tiempo.

El informe redactado por el doctor Luis de Villanueva Zapata y dos alcaldes mayores, con experiencia en reducciones, justificaba la realización de las congregaciones de pueblos de indios al interior de los reales de minas. ${ }^{16}$ Empezaron su declaración manifestando que se había creado una falsa idea sobre los agravios recibidos por los indios en las minas. De acuerdo con sus postulados, no eran, precisamente, los indios naboríos o que trabajaban libremente en ellas quienes sufrían dichos dańos, sino que ya venían con ellos los indios que iban forzados con el repartimiento. Otro tópico que querían desterrar de la visión que se tenía del trabajo en las minas eran los accidentes; para ellos, los percances que acaecían en las minas no eran más relevantes que los que podían ocurrir fuera de ellas. Las supuestas bondades de las reducciones de indios en los reales mineros fueron formuladas por los ejecutores de este informe. Así, sostenían que los indios congregados en el interior de los reales de minas vivirían con mayor dedicación y riqueza que en sus pueblos; no sólo trabajarían en las minas sino en otros oficios necesarios como piqueros, trajineros de bastimentos, acarreadores, albańiles, carpinteros. El ejemplo de estas "bondades" lo situaban con los indios naborías o libres, que se encontraban recios y fuertes, pareciendo otro "género de gente" en relación con otros indios. Pero sin duda alguna, la gran bondad de las minas era la riqueza que producían. Gracias a ella, Nueva España vio aumentada su población de espańoles, pero sobre todo sirvió para la "defensa y exaltación de la fe católica". Y este desarrollo dependía

16 "Apuntamientos de las razones y causas que se ofrecen por la parte de que las congregaciones y poblaciones de yndios que se an de hacer dentro o fuera de las minas para el socorro y mayor beneficio dellas en población con traza y polecía de calles alrededor de las casas del alcalde mayor", ff. 212r-215v. 
especialmente del sistema de trabajo en las minas, que los defensores de las congregaciones de pueblos de indios en el interior de los reales mineros defendían y promovían. Villanueva y los alcaldes mayores señalaban que los indios recibirían allí menos vejaciones, por parte de españoles, mestizos y mulatos, al contar con el apoyo del alcalde mayor de minas, ministros de doctrina y alguaciles, quienes velarían por su seguridad. Incluso, los vecinos y mineros serían los mayores interesados en no consentir que se les hicieran vejaciones y malos tratamientos. Sin embargo, en las congregaciones emplazadas fuera de los reales de minas podría acontecer que "mestizos, mulatos y negros tendrán por pasatiempo el ir a quitarles lo que tuvieren y es imposible poderles asegurar la justicia de estas vejaciones".

El informe destacaba el descanso como un beneficio para los indios que se congregasen dentro de los reales de minas. Éste sería más significativo que el que recibirían viviendo fuera, especialmente porque estarían más cerca de su casa y de su familia. Otra ventaja que presentaba el vivir al interior de los pueblos de minas la constituía el control de las enfermedades graves, como el cocoliste. Los mineros, por el interés que les generaba el trabajo en las minas buscarían remedios para tales males. Las relaciones entre los caciques indígenas y los mineros son tratadas en la parte final del informe. En este punto, los mineros criticaban el control que las autoridades indígenas ejercían sobre los indios en sus pueblos de origen aprovechando el repartimiento o coatequitl. Por el contrario, si se hicieran las congregaciones al interior de los reales de minas, los indios estarían exentos de pagar tributos y servicio personal, "que son las mayores cargas que padecen en sus pueblos". Los autores de este informe argumentaban que en aquellos lugares donde los repartimientos de indios eran importantes, como era el caso de los alrededores de las minas de Pachuca, el ocaso de las congregaciones era evidente; mientras, el aumento de las poblaciones dentro de las minas de Taxco era una realidad, precisamente donde había menor repartimiento de la población indígena.

El documento final del expediente que presentamos echa por tierra las pretensiones de aquellos que defendieron en su informe el establecimiento de las congregaciones de indios dentro de los reales de 
minas. ${ }^{17}$ En él se recogen las medidas que la Corona ya había tomado al respecto. La intención de las autoridades metropolitanas era fundar poblaciones de indios en los contornos de los centros mineros y no al interior de los mismos. Estas medidas se vieron refrendadas por una real cédula de 24 de noviembre de 1601, precisamente cuando el virrey conde de Monterrey estaba a punto de iniciar en Nueva Espańa las conversaciones y discusiones con los sectores interesados en las congregaciones de pueblos de indios en los reales de minas. Según la disposición, era preferible fundar pueblos de indios en los contornos de los reales de minas en lugar de traer indios de repartimiento, que en muchos casos se trasladaban de pueblos distantes con lo cual recibían daños y perjuicios. El plan era que en sitios cómodos y sanos, en los perímetros de los reales de minas, se fundaran pueblos, con su doctrina y hospitales. El procedimiento por seguir era lo ordenado con el mismo fin para el Cerro de Potosí. ${ }^{18}$

A continuación presentamos la transcripción de este relevante expediente, producto de la histórica etapa de aplicación y desarrollo de las congregaciones civiles de pueblos de indios que se llevó a cabo en el virreinato de Nueva España entre finales del siglo Xvı y principios del siglo XVII.

\section{TRANSCRIPCIÓN DEL DOCUMENTO ${ }^{\text {I9 }}$}

\section{|| [206r] De oficio. Si conbendrá hazerse poblaciones de indios en los reales de las minas donde trabajan o fuera de ellas. Mayo, 1603.}

El virrey de Nueva Espańa en carta de 2 de diciembre de 1602 escribe que será necesario responder al capitulo 14 de carta de gobierno temporal, en razón de que las poblaciones de indios en las minas sean dentro dellas o fuera.

17 "Copia de un capítulo de los contadores de los servicios personales que trata de los yndios que tenor trabajan en las minas de sus poblaciones en el contorno dellas", f. 216r.

${ }^{18}$ Recopilación de las Leyes de los Reinos de las Indias, libro VI, tít. III, ley x, Madrid, Ediciones Cultura Hispánica, 1973, 199.

${ }^{19}$ En la transcripción se ha respetado el texto original y las abreviaturas se han desarrollado utilizando cursivas. 
Escribe en carta de 25 de mayo del mismo año, escribe lo que en cuanto de esto tiene ordenado y le pareze.

El Consejo mandó que se le escriba lo que de la experiencia que dice había de hacer ha resultado.

Traense los inconvenientes que resulta de estas poblaciones y unos apuntamientos del Doctor Luis de Villanueva Zapata cerca de esto, de 28 de mayo de 1602.

Vistos en 14 de mayo de 1603

[rúbrica]

|| [206v] De officio para verse luego

[Al margen. Título del documento]. Lo que ha escripto el conde de Monterrey acerca de la población de los indios que trabajan en las minas dentro de los Reales dellas o fuera. Sobre que pide respuesta y traese lo que hay en ello como lo ha mandado el Consejo.

||[207r] Copia de un capítulo de carta que el conde Monterrey escribió a Su Majestad en carta de 2 de diziembre de 1602.

[Al margen: Tráigase lo que se ha respondido en esto] De muy grande inportancia será que al recivo de esta se aya servido Vuestra Magestad de responder al capítulo catorce desta misma carta de gobierno temporal en razón de lo que al Consejo oviere parecido más conviniente cerca de que las poblaciones de indios en las minas sean dentro dellas o fuera. Escribí largo sobre esto en la carta dicha y no lo repito porque fue duplicada en la varca tras la flota y por La Habana en los galeones, si no se oviere despachado la respuesta [Al margen: no hay tomada resolución] suplico a Vuestra Magestad que venga luego, aunque para esto solo se aya de enviar un barco porque en caso tan grave pueda alcanzar antes de la execución que tengo reservada para abril y mayo la enmienda que conviniere poner en lo que acá a parescido sobre la duda y perplejidad que en esto tubieron las personas que lo vieron y dieron su parecer por mi orden.

Concuerda con el original

Pedro Ortes [rúbrica y firma] 
Vistos en 14 de mayo de 1603 en el Consejo por los señores Baltodano y Armeros.

[rúbrica]

\section{|| [208r] Copia de un capítulo de carta del conde de Monterrey} para Su Majestad de 12 de mayo de 1602.

Haviéndome cuadrado mucho la plática que allé en este Reyno de proveer a las minas gente haciendo población en ellos, no me pareció tratar del efecto asta ver si se avía de acometer la redución general proveerse claramente que aquel movimiento de todo el reino podría facilitar mucho estotro negocio y darle buena sazón. Y luego que se determinó que se congregasen los indios me pareció conferir de las poblaciones dichas y por el año de noventa y ocho hice junta de algunos oydores y de religiosos en razón de ver si sería más justo y conviniente que se hiziesen en los Reales de minas o en su cercanía, y no me quise determinar este punto asta mayor deliveración respeto de yrse alargando las demarcaciones de las provincias y no se poder executar en muchos días la redución general ni por consiguiente las poblaciones de las minas pues hera menos ynconbiniente dilatarse un año o dos que acometerlo a solas. El año de noventa y nueve siguiente me mandó Vuestra Magestad. escrivir que favoreciese mucho a los mineros en quanto buenamente se pudiese y señaladamente en algunas cosas y ésta entre ellas, y que en estas materias me ynformase de personas ynteligentes y particularmente del doctor Villanueva. Este doctor, como deví de escrivir entonces, lo es mucho porque demás del subjeto y letras y buena presunción tiene muy buenas haciendas de minas que tanvién le representavan ynteresado en lo que se pretende no estava en la ciudad en aquel tienpo ni vino mucho después ni el negocio tenía sazón. Ya este año de mil y seiscientos y dos le tiene por estar propincua la execución en las congregaciones de esta provincia de México a donde caen las minas principales, || [208v] y assí he mandado apurar este negocio y encargado al dicho doctor buena parte del cuydado, ordené que se hiciese últimamente una conferencia delante de mí sobre el punto referido de la situación de las poblaciones dentro de los eales o fuera por haber yo dudado en ello y sentido Vuestra Magestad de la misma duda en lo que 
después mandó escribirme. Halláronse presentes el licenciado Antonio Maldonado, oydor de esta Real Audiencia, y tres religiosos de los más graves y doctos que aquí tiene la Compañía, y concurrieron tanvién el doctor Villanueva y otros dos onbres principales de aquí, personas de buena yntiligencia y de experiencia para el propósito por haver sido alcaldes mayores en las congregaciones de minas. De mayor ynportancia y grosedad de veneficio confiriose la dificultad en mi presencia con mucha atención y buenos discursos. Del licenciado Maldonado y a los tres teólogos pareció que estas poblaciones se yciesen fuera de las minas, en alguna cercanía, aunque se alargue la distancia asta cuatro leguas. El doctor Villanueva y los dos alcaldes mayores de minas aprehendieron lo contrario fuertemente y sienten que no solo para el vien de la misma cosa en lo que se pretende de dar avío y socorro de gente a las minas, sino para el anparo, buen tratamiento y mayor comodidad de los indios, conviene que sean estas poblaciones entre las cassas de los mineros y otros vecinos espańoles que avitan en los Reales, y lo mismo sintió el Doctor Eugenio de Salazar antes de su promoción al Consejo quando el año de noventa y ocho, como ya dixe, se trató deste propio punto, y los que asistieron entonces fueron él y el dicho licenciado Antonio Maldonado y dos padres de la Conpañía de los tres que aora intervinieron. Y no me a parecido negocio de confundirle con mucho número de pareceres, yo veo que están encontrados y a mí realmente se me a representado sienpre desde los años pasados que lleva mucho

|| [209r] camino el ser menores las vexaciones en la población de yndios que se asentare dentro que en las vecinas. Y me haze mucha fuerza por esta parte la experiencia que tienen de las cosas de minas los que fueron aora de este parezer y el considerar que esta experiencia no la tienen los demás. Y así fundan el suyo en los discursos, y como Vuestra Magestad sabe, y se ve cada día, estos suelen faltar y son de menor fundamiento para los puntos de que se trata que solamente son si será más vexación de los yndios estar poblados en los reales mismos que estarlos en sus cercanías y si va a decir mucho de lo uno a lo otro para conseguirse medianamente los efectos que se pretenden en el augmento de plata da lo menos en la conservación de la que oy se sabe, se saca y beneficia, en esto postrero serán muy cortos los que 
resultaren si las poblaciones se hazen a tres y a quatro leguas de distancia, y aunque a una legua o algo menos no serán tan grandes con mucha parte como si se hiciesen dentro y en medio de las haciendas y alrededor de la casa del alcalde mayor. No me llevaría a mi tanto esta diferencia quanto el mirar al primero punto de la menor vexación de los yndios poblando dentro, más viendo tan partido esto en opiniones y que para el general sentimiento de los naturales y de sus ministros de doctrina y encomenderos suena con menos dureza el ponerlos en cercanía de las minas, quando determinado de mandarlo ansí y por la provavilidad que tengo de que a de serles esto peor y de más agravios me ynclino a ordenar [Al margen: Decreto] [Al margen: Que se le responda que hágase lo que por experiencia resultare] que en uno o dos asientos de minas se pruebe el poblarlos dentro del real para consultar la expiriencia en esta duda, si antes que llegue la razón de ponerse mano en poblar estos asientos y la cercanía y vecindad de los restantes que será dentro de ocho meses lo juz-

|| [209v] gare Vuestra Magestad diferentemente en el Consejo y se determinare de encomendar algo en esta resolución será Vuestra Magestad servido de que se despache un barco sin dilación alguna con el mandato de Vuestra Magestad porque llegue a tiempo, pues ay lugar que yo no haviendo llegado nueva orden dareme por entendido de que no la ay, y mandare que se vaya executando sin que se pasen los meses que se siguen al de henero, que es tienpo sereno y en que no llueve, y por estar la cosecha acavada tienen más desenvarazo los indios, y para que más por menudo conste al Consejo de los motivos y razones principales de cada una de las opiniones conforme a lo que se confirió en la junta ynvió con esta sendos papeles distintos y cada uno examinado por persona de aquel docto porque el padre Morales, de quien va firmado un billete en que dize averlas visto y comunicado al oidor Maldonado y que en sustancia va puesto todo bastantemente, es uno de los tres teólogos de la junta y lo mismo dize el doctor Villanueva de el papel que aze en favor de la opinión que él y los alcaldes mayores tubieron.

Concuerda con el capítulo de la carta Pedro Ortes [rúbrica y firma] 


\section{|| [210r] [Los inconvenientes que tiene la población de yndios} dentro de las minas y las convenencias que se seguirán haciendo fuera y lo más cerca que se pueda]

Cerca de la dubda que se ofrece del modo en que las congregaciones en las minas serán más a propósito dentro o fuera dellas por la segunda parte de que sean fuera se ofrecen las razones y causas siguientes:

Lo primero, se considera la naturaleza del indio en sumo dode vivir y de su ynclinación que todo es en el campo y apartado de espańoles y en el beneficio y lavor de sus tierras y en el gusto de criar algunos árboles y ortaliza que es la grangería que le basta para su sustento y la paga de sus tributos, y si le meten a bibir y poblar dentro de las minas carece de todo esto y se le a de seguir tan notable desconsuelo y aflicción que se muera, o a lo menos se huya y ausente de la congregación.

Lo segundo, se considera el odio natural que los yndios tienen al servicio de las minas y por expiriencia se sabe lo mucho que siente el yr a ellas, aunque sea por corto y breve término, y el día que con fuerza y biolencia se hallasen obligados a yr de asiento y a aber de bibir en los mismos Reales de las minas y entre los mineros y fuera de lo que es su natural como es gente miserable y de tampoco ánimo y con quien tanpoco bale el ynterés que se les puede seguir, y los mineros les ofrecerán aunque lo cumplan es de presumir por muy cierto que sin atender a nada no an de permanecer en las poblaciones.

Yten se considera la dureza grande que tiene siendo las poblaciones dentro de las minas forzar y necesitar

|| [210v] al yndio a que biba a boluntad y merced del minero y que no tenga como no lo terná de que sustentarse ni de dónde sacar un tomín sino de lo que el minero le quisiere dar, y es berisímil que teniendo los mineros tan cerca de sí, y biendo que no pueden bibir ni sustentarse sino de lo que les quisieren dar, los an de tener como a esclavos, y acaecerá muchas veces que habiendo concertado con ellos el servicio que les an de hacer en el beneficio de los metales fuera de las minas teniéndolos ya obligados les conpelerán a entrar 
en ellas, que siendo trabajo tan grande y cosa de que no tienen ninguna espiriencia se infiere fácilmente lo que se dice de que se huirán y ausentarán por librarse de ellos.

Yten se considera la bexación y molestia continua que ternan siempre de los mineros y de sus criados y esclavos de día y de noche, saltándoles las paredes y entrando en sus casas a tomarles lo que hallaren de gallinas o otra qualquiera cosa que tengan, y aún podría estenderse a las mujeres e hijas. Y aunque fuera de las minas no estarán seguros de estos daños, todabía muchas veces por no andar una o dos leguas de distancia y otro tanto camino a la vuelta dexarán algunos de hacérsele, o a lo menos no será tan de hordinario como si se poblasen dentro de las congregaciones, ni ansí y qual con mucha parte a lo que asta ora corría en las cercanías por haber sido después chicos y a haverse agora de poblar en congregación numerosa y demás defensa y con ministro de doctrina asistente y en algunos de corregidor que, como ministros propios y que no tienen otro caudal de súbditos, miran por ellos y por su amparo lo que no ternán poblados entre los mineros y con recurso al alcalde mayor de las minas que de hordinario es y deseasen

|| [211r] compadre de todos y tiene ynterés en el beneficio de las haciendas.

Yten se considera que como en los travajos grandes y cosas dificultosas no es bien entrar con miedo ni espanto que si estas poblaciones se hacen fuera de las minas por el gusto y mayor suavidad de los yndios con la vecindad de los mineros, y con lo que abrán de acudir al servicio personal y conducidos voluntariamente, como lo harán muchas veces, irán perdiendo este miedo y aborrecimiento natural y se irán pasando a bibir dentro de las minas y haciéndose laboríos y barreteros. Y con el ejemplo de los primeros, y viéndolos los demás que de aquello resulta probecho y menos travajo y riesgo, de el qual principio ymajinarán se irán aficionando otros a este modo de vida y conseguirán los mineros el fin que desean de tener gente.

Yten se considera el cuidado que el minero terná de atraer con caricia, regalo y buena paga al yndio, si estos an de ser medios para hacerles su laborío y aficionarle a las minas y a que dexe el campo y su pueblo, y que por el contrario si le tiene tan cerca de su casa y le be 
necesitado a que para comer y sustentarse a de bibir con él le tratara como a esclavo o mucho peor y será causa de lo que está dicho de su huida y mayor aborrecimiento de las minas y de que no se consiga ni aún en pequeña parte el fin que se lleba de hacerles su laborío.

Yten se considera el ánimo que le porna al yndio para yr al servicio de las minas conducido boluntariamente

|| [211v] el saber que al cabo de ocho días, o un mes de trabajo, podrá bolverse a su casa y huerta y tierras a descansar otro tanto tiempo o el que quisiere, y para yr al repartimiento el saver que cumplida su semana a de olgar muchas hasta que le quepa otra vez, y si la población ubiese de ser dentro con el trabajo exsecivo y la falta desta esperanza es muy de temer todo lo que sea dicho de su huida o muerte.

[Al margen. Título del documento] Los ynconvenientes que tiene la población de yndios dentro de las minas y la convenencias que se seguirán haciendo fuera y lo más cerca que se pueda.

Cítalo el capítulo 14 de la carta de gobierno temporal

|| [212r] Apuntamientos de las razones y causas que se ofrecen por la parte de que las congregaciones y poblaciones de yndios que se han de hacer dentro o fuera de las minas para el socorro y mayor beneficio dellas en población con traza y polecía de calles alrededor de las casas del alcalde mayor.

1. Lo primero, se considera y adbierte que la boz general que a corrido y corre de los agravios que los yndios reciven de los mineros en la parte que es cierto, no son estos los yndios laboríos que los mineros tienen en sus casas, ni cuadrillas para dentro y fuera de las minas sino de los yndios que ban forzados y de repartimiento.

2. Lo segundo, se advierte que algunos sucesos que ha avido en las minas de caídas y otros casos, de que an resultado algunas muertes de yndios, no son hordinarios sino accidentales y sucedidos acaso como se an bisto más o menos en todos los demás géneros de servicios que los yndios hacen. 
3. Yten, se advierte y considera el poco o ningún fruto que se terná de estas congregaciones de yndios siendo fuera de las minas para el efeto que se desea de socorrer las haciendas y augmentar el beneficio que va tan de caída, y para esto se presume que se pueda hacer en la cercanía de algunas minas una o dos poblaciones que tengan mil yndios como los ha habido en algunas partes y se han acabado, o en muchas congregaciones pequeńas, según la capacidad de los puestos, siendo tan conocida la pereza del yndio y la mala ynclinación que tiene a todo género de trabajo, el mayor fruto que de esta población de yndios les resultara a las minas no es más del cuarto por ciento el que se les augmentara en el repartimiento, que aún cuando || [212v] se cobre de mil yndios serán quarenta tapixques, y como la falta que se desea suplir no es de yndios sino de barreteros no es de consideración ninguna este socorro ni de la condición del yndio se podrá esperar que teniendo de que sustentarse por miserablemente que sea como no puede con ellos casi nada la codicia, ni buscan más de lo que forzosamente han menester. Para su sustento nunca de su voluntad querrán conducirse y en la sustancia de lo que se pretende no se conseguirá nada y en el beneficio de los metales pocas y los yndios habrán de quedar en menos buen asiento del que los demás tienen de tierras y aguas.

4. Yten, se considera y pone delante que asentados los yndios en población dentro de las minas, aunque les faltase el uso de sus sementeras, bibirían con mucho mayor descanso y riqueza que la que en sus pueblos y grangerías de labranza pudieran tener porque abrá para todos ocupación y entretenimiento de probecho, los unos sirbiendo a los mineros en sus haciendas, y otros en diferentes oficios a que los yndios se aplicarán todos necesarios para las congregaciones y Reales de minas, como son piqueros y tragineros de bastimentos, acarreadores de los metales desde las minas a las haciendas, albañiles, carpinteros y todos los demás oficios como los usan en esta ciudad de México y en todas las demás poblaciones de españoles donde ay yndios, y esto se sabe conocidamente que le es de tan grande ynterés que gana un yndio oficial cada día seys, siete reales y algunos más y la parte de yndios que se aplicare a servir a los mineros también terná mucho interés, mayormente los indios barreteros 
|| [213r] y que entran dentro de las minas por lo que se save y ve cada día de sus pepenas y de lo que acontece ser cuantiosas demás del salario grande que los mineros les dan, en que se considera que no todos los días entra el yndio en la mina, ni el día que entra está de quatro oras arriba, y el cuidado que el minero pone en regalar y acariciar a este yndio curándole en sus enfermedades y socorriéndole en todas sus necesidades como a hijo, por lo que le importa para el beneficio de su hacienda, y porque no se le baya de descontento o mal pagado a servir a otro minero, y así andan todos estos yndios naboríos tan recios y fuertes, bien tratados, que entre los demás yndios parece otro género de gente y no corre ninguna otra razón que el mejor sustento y tratamiento que tienen, y siendo tan cierto y berdadero esto como realmente lo es no parece que se deve huir de poner al indio en ocasión de servir al minero, pues si estubiera mejor distinto para conocer quan bien le está y se persuadiera a trabajar algo con un poco de riesgo accidental por la cudicia de tan gran premio sobrará en las minas mucha gente demás de que no se entiende que todos los yndios que sirven a los mineros será en la ocupación de cortar y sacar los metales porque tanbien se ayudarán de ellos en el beneficio de los metales que se haze en los yngenios sin ningún género de riesgo, como se ayudan y sirven de los tapixques de repartimiento, y como hallen gente conducida de su voluntad y con más práctica de este beneficio que la que los tapixques de repartimiento tienen, también es cierto que les harán muy buen tratamiento como los laboríos y aunque no tan

|| [213v] gran paga doblada que a los de repartimiento, porque al cabo de poco tiempo estaban con la costumbre tan diestros en el modo del beneficio que con menos travajo que otros supla uno de estos por dos tapixques.

5. Yten, se considera y adbierte los grandes efectos que se an hecho y hacen en servicio de nuestro Señor y de Su Magestad con la riqueza de las minas, pues en tan pocos años como ha que se pacifica esta tierra ha crecido la población de españoles al estado que oy tiene, y Su Magestad y sus antecesores han podido mejor acudir a la defensa y exaltación de la fe cathólica de que en estos tiempos ha avido y ai tan grande necesidad, y es cierto que quanto mayor fuera el socorro 
que se enbiare a Su Magestad tanto mejores y mayores se pueden esperar estos efectos, y este depende y resulta precisamente del medio y punto sobre que se trata.

6. Yten, se considera y adbierte el más cierto y seguro amparo que los yndios ternán en las vexaciones y molestias que suelen recivir de los españoles, yndios, mestizos y mulatos estando dentro de las minas, donde a qualquiera necesidad hallan cerca el alcalde mayor dellos, y a su ministro de doctrina y a los alguaciles que los defiendan y amparen, que todos han de bibir y tener sus casas en medio de la población de los yndios y no sólo ternán este amparo en las justicias y ministro de doctrina sino aún en los mismos vecinos y mineros, pues es cosa cierta y de buena razón que ningún español dexa de faborecer al yndio quando llega a tiempo que le están agraviando o maltratando, y como todos los mineros y aún los españoles

|| [214r] que les ayudan al beneficio de los metales serán interesados en el buen tratamiento general de los indios, de creer es que no consintirán que se les haga vexación, y estando estos yndios en distancia de las minas a legua o legua y media o poco más o menos, los mestizos, mulatos y negros ternán por pasatiempo el yrles a quitarles lo que tuvieren, y es inposible poderles asegurar la justicia de estas vexaciones, porque dado caso que el pueblo benga a ser de quinientos tributarios que por la ruin dispusición de las cercanías a lo menos en la mayor parte de las minas no parece caso tolerable que puedan sufrir justicia de asiento respeto de lo mal que podían sustentarle, y quando aya persona que quiera acetar tan corta comodidad es berisímil que no será de las partes ni satisfacción que se podrá tener de la persona del alcalde mayor de las minas que en todos es hombre de lustre y suerte, y en algunos de los más principales sujetos del reino para que no consienta en los agravios de los yndios ni disimule con los que se los hicieren, pues de ninguna manera es de presumir de los tales especialmente en casos de opresión y biolencia y tanbién se consideran los agravios que les harán los pasajeros y gente de la comarca que en todo se experimenta oy en los pueblos de los indios y será muy diferente dentro de las minas como se ve en las ciudades y villas de españoles donde ay congregaciones y barrios de yndios. 
7. Yten, se considera y adbierte de que estando estos yndios fuera de los reales de minas, con el cuidado, necesidad y deseo que los mineros tienen de haver gente, es muy cierto que han de poner mucha diligencia en traer yndios a sus haciendas enbiándoles dinero adelantado o cohechando a sus mandones para que se los bendan y después de tenerlos en sus casas como cosa accidental y que no esperaran

|| [214v] de tornar a tener aquellos mesmos yndios no les haránn mejor tratamiento ni aun tan bueno que a los yndios de repartimiento de que le causara mayor aborrecimiento que el que tienen a las minas y si se bieren adeudados y prendados con los mineros por no bolberlos a serbir y por huir de que sus mandones no los buelban a bender y mirado la poca bentaja de comodidades y grangerías que tienen en sus congregaciones se huirán dellas y esto de que sus mandones los vendan al minero con frequencia se puede temer mucho y aun es cierto que susederá muy de hordinario porque no ternán otra cosa de que aprobecharse para sus provechamientos y aun de las justicias se puede temer lo mismo si no fueren personas de entera satisfacción y es ymposible como está dicho poderse poner de esta calidad con asistencia en estas congregaciones.

8. Yten, se considera el descanso y regalo que será para el indio que habiendo trabajo todo el día o buena parte de él se hallase a pocos pasos en su casa cada noche y con la compañía de la mujer e hijos y estando desviada esta población le es de tanta molestia la distancia del camino y la ausencia de su casilla como el trabajo que ha tenido. 9. Yten, se considera que siendo estas poblaciones dentro de las minas no sólo no solo los hombre ternán ganancia y probecho sino tanbien las mujeres y muchachos en el labar de los metales y acudir a otras cosas que les serán útiles.

10. Yten, se considera el socorro y amparo que los yndios ternán si les sucediese cocoliste u otra enfermedad general en un pueblo, como se ha visto, porque apenas abrá yndio que por un camino o por otro no tenga dependencia con minero

|| [215r] y por su propio ynterés les han de curar y regalar. 11. Yten, se adbierte y considera que dado caso que algunas personas entienden que el yndio tubiera por más a libre ser congregado 
fuera que dentro de las minas, quando esto se deviera mucha atención que no deve por la manifiesta cortedad del natural suyo, que no a dado ni da lugar a moberse al govierno por su elección que de ordinariamente se debía, de lo que más les importa pesaba más el bien y utilidad conocida que está por esta parte de poblarlos dentro del real de las minas por todas las consideraciones dichas y por otras mayores de gozar por este medio libertad de tributo y servicio personal, que son las mayores cargas que padecen en sus pueblos, lo cual se funda por la real cédula de exsención executoriada por el Consejo que despone, en cuanto a los tributos y por la clara razón de gobierno que justifica, el no usar ni consentir repartimiento de servicio personal en los yndios poblados en las minas, aunque por necesario se tolera en los pueblos convecinos en que andan ocupados casi la tercia parte del tiempo los yndios plebeyos, no porque el quarto por sí obligue a esto, sino por la ynfidelidad de los mandones, y en pueblo donde será esta la mayor grangería es de presumir que de hordinario les harán estos agravios muy de hordinario.

12. Yten, se adbierte por la razón y causa muy considerable que siendo estas poblaciones dentro de las minas se puede esperar que probeídos los mineros de gente, así para dentro de las minas como para el beneficio que se hace fuera, se podrán ir lebantando los repartimientos de las cercanías, que es una carga tan pesada y inescusable aunque se hallase camino, para que puedan cesar todos los demás géneros de servicio personal de la Nueva España

|| [215v] ofreciese por argumento poderoso lo que se ha visto de acabamiento de los pueblos y congregaciones que cayeron cerca de las minas de Pachuca, con lástima de algunos encomenderos principales, y el augmento que se vio en las poblaciones que hubo dentro de Taxco que en razón de lo uno y de lo otro se siguió pleito en esta Real Audiencia y están bibos los procesos.

En la Junta que su Señoría del conde de Monterrey virrey de esta Nueva España mandó hazer en su presencia sobre la conveniencia destas congregaciones se refirieron todas estas razones, y otras algunas, en la concurrencia que uvo por averse dividido los pareceres casi igualmente, y todas las personas de experiencia que allí asistieron, 
que fueron los alcaldes mayores que an sido y son de las minas más principales de este Reino, tuvieron y defendieron esta parte de que las congregaciones son más útiles para los mismos yndios y para los mineros dentro de los mismos reales, cuyo parecer a sido siempre el mío, aviendo mucho años a, considerándolo atentamente y hecho experiencia por mi misma persona, y juzgado y visto juzgar muchos casos y negocios contringentes de esta materia, de que no se puede hazer bastante y acertado juizio faltando la experiencia, y moviéndose por ventura, con solo la mala estimación que se tiene de los mineros en el tratamiento que hazen a los yndios que realmente si alguno ay malo no es con los laboríos, después acá lo e conferido con las mismas personas de la Junta que huvieron este parecer y con otros muchos de buena ynteligencia y experiencia, y tienen el mismo, y así lo continúo yo y lo firmo en México a 28 de mayo de 1602.

Doctor Luis de Villanueva y Zapata

[Rubricado y firmado]

|| [216r] Copia de un capitulo de los contadores de los servicios personales que trata de los yndios que tenor trabajan en las minas de sus poblaciones en el contorno dellas.

Que por no ser menos conveniente la lavor y veneficio de los otros asientos de minas de oro y plata que ay en las provincias del Perú, Quito, Chile y otras partes, conviene que quanto dellos se tenga el mismo cuydado de fulanos y veneficio que el que se a de tener del dicho cerro de Potosí procurando para esto que se agan poblaciones de indios en contorno de los dichos sitios donde bivan, descansen y se recoxan los yndios que se obieren de ocupar en la lavor y veneficio dellas y para que se pueda tener el cuydado que conbiene con su educación y doctrinas, que aya ospitales donde se curen los enfermos haciéndose particular diligencia para que sanos y enfermos sean bien tratados y para que se conserven de su voluntad, sin que sea necesario que de más lexos vengan otros por repartimiento para lo que ellos pudiere y obieren de hazer, y quando fuere forzosos traer algunos sea de los lugares más cercanos a las minas donde obieren de travajar sin que 
muden temple de tierra fría a caliente ni por el contrario, pagándoles sus jornales desde el día que salieren de sus casas hasta que buelban a ellas y después de llegados a los asientos el tiempo que estubieren en ellos, y travajaren en la lavor y veneficio de las minas señalándoselos de manera que sean conpetentes y acomodados conforme al trabajo, industria y ministerio de cada uno para que sean gratificados suficientemente y pagados con toda puntualidad, teniendo tan vien efecto consideración a que los mineros puedan seguir y veneficiar sus minas con tal comodidad que antes su lavor baya en aumento que en disminución.

|| [216v] [Al margen. Título del documento] Nueva España año de 1603

De oficio sobre si conbendría o no poblar en las minas donde trabajan los yndios o fuera de ellas. 